\title{
Hunger in young children of Mexican immigrant families
}

\author{
Margaret Kersey*, Joni Geppert and Diana B Cutts \\ Department of Pediatrics, Hennepin County Medical Center, Minneapolis, MN 55415, USA
}

Submitted 16 November 2005: Accepted 11 October 2006

\begin{abstract}
Objective: To measure rates of hunger and food insecurity among young US-born Latino children with Mexican immigrant parents (Latinos) compared with a nonimmigrant non-Latino population (non-Latinos) in a low-income clinic population. Design, setting and subjects: A repeated cross-sectional survey of 4278 caregivers of children $<3$ years of age in the paediatric clinic of an urban county hospital for a 5-year period from 1998 to 2003. A total of 1310 respondents had a US-born child with at least one parent born in Mexico. They were compared with a reference group comprised of non-Latino US-born participants $(n=1805)$. Child hunger and household food insecurity were determined with the US Household Food Security Scale.

Results: Young Latino children had much higher rates of child hunger than nonLatinos, 6.8 versus $0.5 \%$. Latino families also had higher rates of household food insecurity than non-Latinos, 53.1 versus $15.6 \%$. Latino children remained much more likely to be hungry (odds ratio $(\mathrm{OR})=13.0,95 \%$ confidence interval $(\mathrm{CI})=5.9-28.7$, $P<0.01)$ and in household food-insecure households ( $\mathrm{OR}=6.6,95 \% \mathrm{CI}=5.2-8.3$, $P<0.01)$ than non-Latinos after controlling for the following variables in multivariate analysis: child's age, sex, maternal education level, single-headed household status, family size, young maternal age $(<21$ years), food stamp programme participation, TANF (Temporary Assistance to Needy Families, or 'welfare') programme participation and WIC (Women, Infants, and Children) usage, and reason for clinic visit (sick visit versus well-child).

Conclusion: Young children in Mexican immigrant families are at especially high risk for hunger and household food insecurity compared with non-immigrant, non-Latino patients in a low-income paediatric clinic.
\end{abstract}

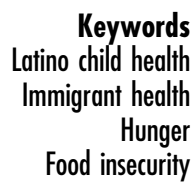

Poor children in America have high levels of hunger and household food insecurity ${ }^{1,2}$. While hunger is a poor outcome in itself, it is also a risk factor for poor health and impaired development. Hungry children have more colds, headaches and stomach aches ${ }^{3,4}$. Children experiencing hunger have decreased school performance and increased behavioural problems ${ }^{5,6}$. Household food insecurity, or limited or uncertain availability of nutritionally adequate and safe foods ${ }^{7}$, is also associated with poor health outcomes among young children ${ }^{8}$.

Previous studies suggest that Latino children in immigrant families may be at greater risk for hunger and food insecurity than other children. Kasper et al. demonstrated a very high prevalence of hunger among Latino immigrant adults?. Analysis of National Health and Nutrition Examination Survey III (NHANES III) data found that Mexican-American children are at greater risk for food insufficiency than children of most other ethnicities ${ }^{3}$. Two other studies have found high rates of hunger and food insecurity among low-income Latino children ${ }^{10,11}$.

Latino children in general are also at high risk for other poor health outcomes. Latino children have increased rates of asthma, obesity, diabetes and exposure to environmental hazards compared with the general population $^{12}$. They also have decreased access to health care $^{12}$. Latino children in families who have recently immigrated may be at even higher risk for poor health than other Latino children ${ }^{13}$.

US-born children in immigrant families are typically considered immigrants for the purposes of health services research since their health and well-being is so closely linked to their immigrant parents' health and socioeconomic status $^{13,14}$. Health issues facing Latino children in immigrant families are important in part because of their rapidly increasing numbers. In 2000, 20\% of all children in the USA had at least one foreign-born parent, with over half of these parents born in Latin America ${ }^{15}$. There are $>5.1$ million children in the USA who are the children of immigrants from Mexico ${ }^{16}$. Furthermore, children of Latino immigrants are now found throughout the USA, as immigrant populations are increasing much faster in 'non-traditional' immigrant states than in the six states in which immigrants traditionally settled (California, New York, Florida, Texas, Illinois and New Jersey) ${ }^{17}$. 
For example, in Hennepin County, Minnesota, the site of the present study, the Latino foreign-born population increased from about 3500 in 1990 to 27000 in 2000, representing a $770 \%$ increase in just a decade ${ }^{18}$.

Analysis of the 2000 Census indicates that the poverty rate for children in immigrant families is much higher than for children in native-born families, at 21 versus 14\%, although the data are not presented for specific ethnic groups or country of origin ${ }^{19}$. Thus, the present study aimed to measure rates of hunger and food insecurity among US-born Latino children with Mexican immigrant parents compared with the native-born non-Latinos in a low-income paediatric clinic population.

\section{Methods}

\section{Informed consent}

Caregivers gave permission for chart reviews as part of the informed written consent process. The study was approved by the Institutional Review Boards at Hennepin County Medical Center and the University of Minnesota.

\section{Setting and participants}

A total of 4278 caregivers of children $<3$ years of age were surveyed in interviews from 1998 to 2003 in the paediatric clinic and the paediatric emergency department (ED) at Hennepin County Medical Center. The clinic and ED serve a primarily low-income, urban, diverse population. Data were collected at both well-child and acute visits. Approximately one-third of subjects were US-born children who had at least one parent born in Latin America, with $88 \%$ of those born in Mexico. Because of the heterogeneity of Latinos from different countries of origin with respect to cultural differences, socio-economic status, health status and patterns of immigration, we elected to restrict our analysis to immigrant families of Mexican origin. This group of US-born Latino children in Mexican immigrant families (called 'Latinos' in the present study) was compared with the reference group of non-immigrant, non-Latino children (called 'non-Latinos'). Foreign-born Latino children and Latino children of US-born parents, both of whom comprised a very small proportion of the sample, were also excluded. The non-Latino children with foreign-born parents were also excluded, since most were refugees from Somalia, a group with its own unique health issues and benefits usage patterns due to their refugee status. All questions were read aloud to study participants by bilingual interviewers in English or Spanish according to caregiver preference. Although caregivers were eligible to be interviewed every 6 months, only one interview was randomly selected per caregiver. After exclusion of cases with multiple interviews and missing data, the final study groups were as follows: Latinos of Mexican origin, $n=1310 ;$ non-Latinos, $n=1805$; other, $n=1078$ (excluded from analysis). The study participation rate was $96 \%$.

\section{Instruments and measures}

The study consisted of repeated cross-sectional surveys collected for the Minneapolis sample of the Children's Sentinel Nutrition Assessment Program, a multisite survey which includes questions on household characteristics, child hunger and food security, and federal assistance programme participation ${ }^{20}$. Household food security and food insecurity with hunger among children (hereafter referred to as child hunger) were determined using the US Household Food Security Scale, which includes the Children's Food Security Scale ${ }^{21,22}$. The scale was chosen because it has been generally adopted as the 'gold standard' instrument in the USA and because its use permits comparisons with nationwide prevalence data. It has also been used in other studies with Spanishspeaking immigrant populations ${ }^{9,23}$.

Hunger is defined by the United States Department of Agriculture (USDA) as 'the uneasy or painful sensation caused by a lack of food; the recurrent and involuntary lack of access to food" ${ }^{7}$. Food insecurity is a more subtle concept defined as limited or uncertain availability of nutritionally adequate and safe foods or limited or uncertain ability to acquire acceptable foods in socially acceptable ways, ${ }^{7}$. Hunger occurs at the individual level, while food insecurity is measured at the household level. In accordance with the US Household Food Security Scale guidelines, participants had to affirm at least five of the eight child-specific food insecurity items to meet the criteria for 'child hunger' (Table 1). The children's food insecurity items were specifically referenced to the child presenting in the clinic.

\section{Statistical analysis}

Analyses were performed with SPSS for Windows and Stata 8.0. Since caregivers were eligible for re-interview after 6 months, a random number generator from Epi-Info was used to select a single interview date for participants who had been interviewed more than once to avoid bias from

\section{Table 1 Child hunger questions}

All questions refer to the last 12 months.

1. Did you ever cut the size of your child's meals because there wasn't enough money for food?

2. Did your child ever skip meals because there wasn't enough money for food?

3. How often did this happen?

4. Was your child ever hungry but you just couldn't afford more food?

5. Did your child ever not eat for a whole day because there wasn't money for food?

Child hunger statements (answered as often, sometimes or never true in the last 12 months)

6 . We relied on only a few kinds of low-cost food to feed our child because we were running out of money to buy food.

7. We couldn't feed our child a balanced meal because we couldn't afford that.

8. Our child was not eating enough because we just couldn't afford enough food. 
any possible temporal trend. Thus, each data point represents a single and unique child.

Bivariate analyses were calculated using the $\chi^{2}$ statistic. Comparisons of medians were performed with the MannWhitney test. Multiple logistic regression models were constructed to control for likely confounding factors for all outcomes reported.

\section{Results}

Ninety-four per cent of respondents were mothers, 5\% fathers, with grandmothers and foster parents comprising the remainder. The Latino respondents were generally recent immigrants, with a median length of time in the USA of 4 years (data presented as medians due to right skew).

Sample demographics of the Latino versus non-Latino sample are shown in Table 2. Maternal education level was significantly lower among Latinos than non-Latinos, as only about one-third of Latina mothers had 12 years or more of formal education, versus two-thirds of nonLatinos. Latino families had much lower rates of single parent households than non-Latinos, at 38 versus $70 \%$. Because the survey asked about household composition rather than nuclear family size per se, we constructed a 'family size' variable by measuring the ratio of dependent children per adult in each household to reflect the number of children supported by each adult. By this measure, family size was smaller for Latinos than for non-Latinos, with a median of 0.75 children per adult in the Latino household versus 1.33 children per adult in non-Latino families (data presented as medians due to right skew). Nearly all households in both groups contained at least one employed adult, at 98\% for both Latinos and non-Latinos.

The median age of the Latino children in the sample was statistically significantly lower than that of the non-Latino children, at 8 versus 9 months (data presented as medians due to right skew), although this difference is not likely to be of clinical relevance.

Latino families participated in the Women, Infants, and Children (WIC) programme at higher rates than
non-Latinos, at 86 versus $76 \%$, but were much less likely to receive food stamps, at 22 versus $64 \%$. Similarly, Latinos were much less likely than non-Latinos to receive Temporary Assistance to Needy Families (TANF, or 'welfare'), at 33 versus $74 \%$. This is despite the fact that all the Latino children were US citizens by study definition and therefore eligible for participation in the food stamp programme and TANF, regardless of the parents' immigration status, as long as their families met income requirements.

Latino children $(n=1310)$ had much higher rates of child hunger than non-Latinos $(n=1805)$, at 6.8 versus $0.5 \%(P<0.01)$. Latino families also had much higher rates of household food insecurity than non-Latinos, at 53.1 versus $15.6 \%(P<0.01)$.

These results persisted after controlling for the following socio-economic and demographic variables in multivariate analysis: child's age, sex, maternal education level (threelevel variable: less than high school, high school graduate and any post-secondary education), single-headed household status, family size, young maternal age $(<21$ years), food stamp programme participation, TANF programme participation, WIC usage and visit type (well-child versus sick visit). Latino children were much more likely to be hungry (odds ratio $(\mathrm{OR})=13.0$, 95\% confidence interval $(\mathrm{CI})=5.9-28.7, P<0.01)$ and in food-insecure households $(\mathrm{OR}=6.6,95 \% \mathrm{CI}=5.2-8.3, P<0.01)$ than nonLatino children. None of the other covariates in our model were independent predictors of child hunger (all $P>0.05$ ) (results not shown). In the household food insecurity model, increased maternal education level was negatively associated with food insecurity (OR $=0.85,95 \%$ $\mathrm{CI}=0.75-0.96, P=0.01)$, as would be expected. Young maternal age $(<21$ years $)$ was also negatively associated with food insecurity $(\mathrm{OR}=0.66,95 \% \mathrm{CI}=0.52-0.83$, $P<0.01)$.

\section{Study limitations}

The present study has several limitations. First, there has been some question about the validity of the US Household Food Security Scale in Spanish. Although

Table 2 Selected demographics and benefits use, Latinos versus non-Latinos

\begin{tabular}{lccc}
\hline & $\begin{array}{c}\text { Latinos } \\
(n=1310)\end{array}$ & $\begin{array}{c}\text { Non-Latinos } \\
(n=1805)\end{array}$ & $P$-value \\
\hline \% of mothers with 12 years or more of formal education & 36 & 67 & $<0.01^{\star}$ \\
\% of single parent households & 38 & 70 & $<0.01^{*}$ \\
Ratio of children to adults in household ('family size'), median & 0.75 & 1.33 & $<0.01 \dagger$ \\
\% with maternal age <21 years & 16 & 28 & $<0.01^{*}$ \\
Age of child in months, median & 8.1 & 9.1 & $<0.05 \dagger$ \\
$\%$ participating in WIC programme & 86 & 76 & $<0.01^{\star}$ \\
$\%$ participating in food stamp programme & 22 & 64 & $<0.01^{*}$ \\
$\%$ participating in TANF & 33 & 74 & $<0.01^{\star}$ \\
$\%$ of households with at least one employed adult & 98 & 98 & $>0.05^{\star}$ \\
\hline
\end{tabular}

WIC - Women, Infants, and Children; TANF - Temporary Assistance to Needy Families.

${ }^{\star} \chi^{2}$ test.

†Mann-Whitney test. 
a standard translation instrument now exists ${ }^{24}$, it was not available at the time of the study's inception, so a translated instrument was developed and extensively pretested by bilingual translators. Furthermore, the original validation of the USDA scale did not include large numbers of Latinos, and questions have arisen regarding the instrument's validity in this population ${ }^{24}$. However, the scale has recently been validated in at least one lowincome Latino population, as families reporting food insufficiency and/or hunger were found to have decreased amount and quality of foods in their households ${ }^{25}$. If anything, case studies and ethnographic research suggest that the currently used instrument is more likely to underestimate than overestimate the prevalence of child hunger, since parents may be reluctant to admit the extent of the problem out of pride, shame or fear of government intervention ${ }^{21}$.

Secondly, the sample was clinic-, rather than population-based, and there may be a selection bias for Latinos compared with non-Latinos seeking care in the county hospital system overall, independent of visit type. Furthermore, since the data only come from one site, with a sample restricted to immigrants of Mexican origin, these results cannot be generalised to the general immigrant Latino population or even the Mexican immigrant population in the USA.

Thirdly, although we did have substantial demographic information about our study participants, there almost certainly remain a large number of unmeasured confounders which may mediate the relationship between immigration status and hunger and food insecurity.

Finally, since our data are cross-sectional and observational, causality cannot be determined between the exposure (ethnicity and immigration status) and outcome of interest (hunger and food security status), although the temporal relationship is consistent with causality since the exposure by definition preceded the outcome.

\section{Discussion}

The prevalence of child hunger in our Latino sample was $>10$ times the national average in 2003 according the 2003 Current Population Survey, which uses the identical instrument and is representative of the general US population across all income levels ${ }^{26}$. They report a national prevalence of child hunger of $0.5 \%$, compared with $6.8 \%$ of our Latino sample. Using the same data source, $11.2 \%$ of households were food insecure in 2003, compared with $53 \%$ of our Latino sample ${ }^{26}$.

The disparity between the Latinos and non-Latinos in our study is all the more striking because our reference group of low-income non-Latinos had rates of food insecurity only moderately higher than the nationwide average of all households in 2003 , at 15.6 versus $11.2 \%$. Minnesota has among the lowest rates of food insecurity in the nation: analysis of the 1998-2000 Current Population
Survey indicates that the rate of food insecurity in Minnesota during this period was only $7.8 \%$, versus $10.8 \%$ nationwide ${ }^{27}$. Despite the relatively favourable food security status of most Minnesotans during this time period, it is apparent that this did not extend equally to all subpopulations.

In our study population, Latino immigrant children are far more likely to be hungry than non-Latino, nonimmigrant children. This is despite Latino families' higher proportions of dual-parent households and smaller family sizes (measured as the ratio of children to adults per household) than non-Latino families.

The causal pathway between food security status and benefits usage is impossible to determine in a crosssectional survey such as this one. According to our multivariate analysis, none of the food assistance programmes (WIC, food stamps and TANF) was either positively or negatively associated with either child hunger or household food insecurity.

It is probably the case that families elect to participate in benefit programmes precisely because they are experiencing household food insecurity or child hunger. This selfselection of the neediest families makes the true effect of food assistance programmes very difficult to determine. Many studies which examine the effects of WIC, TANF and food stamps are limited by their inability to account for this important potential bias. Nonetheless, at least one study which attempted to control for this self-selection effect using proxy measures from other databases found positive effects of WIC on pregnancy and birth outcomes ${ }^{28}$.

Most of the Latino families in our sample were presumably eligible for child-only benefits, since all the Latino children in our sample were by definition US-born, with at least one foreign-born parent (most of whom were recent immigrants and therefore ineligible for benefits themselves). We hypothesise that the monetary benefit may not be sufficient to motivate participation in programmes designed to protect against household food insecurity or child hunger. These immigrant families' low rate of participation in the food stamp programme for their citizen children despite very high levels of family food insecurity and child hunger is very similar to that of a nationwide study by the USDA, in which only $38 \%$ of citizen children in immigrant families received the food stamp benefits for which they were eligible ${ }^{29}$. Qualitative research has found that immigrant families are often reluctant to receive public benefits such as food stamps even for their US-born citizen children for fear of being named a 'public charge', which may affect parents' later chances of obtaining citizenship or even result in deportation ${ }^{30}$. This belief persists despite the fact that the Immigration and Naturalization Service (now the US Citizen and Naturalization Service) has clarified that receipt of non-cash benefits such as food stamps is not considered in the determination of public charge, particularly when the benefits are for US-born citizen children ${ }^{31}$. Thus, many of the families in 
our study were not accessing much-needed benefits (by their own admission of very high rates of food insecurity and child hunger) despite their presumed eligibility and despite reassurances from the US government that accessing these benefits will not affect family members' current or future immigration status. Further research is needed to determine ways to 'reach out' effectively to immigrant communities to dispel any fear or myths regarding government assistance for citizen children in immigrant families.

It is striking that Mexican immigrant children in this study were at a 13-fold increased risk of experiencing hunger compared with our non-immigrant, non-Latino clinic population even after controlling for many of the socio-economic and demographic variables that might cause children to be at high risk for poverty.

\section{Conclusions}

Young children of low-income Mexican immigrants are at especially high risk for hunger and food insecurity compared with other low-income children in one urban, diverse paediatric clinic population. Public health officials and policy makers should be particularly attentive to the issues of hunger and food insecurity and its effects on child health in this growing high-risk population. While underutilised by low-income immigrant families, present government food assistance programmes may be inadequate to prevent child hunger and family food insecurity even when accessed. Nevertheless, it is critical that any modifiable limitations to enrolment, such as language or literacy barriers, cumbersome bureaucracy, and confusion or misinformation, be minimised in order to moderate the severity of child hunger. Efforts directed towards achieving health equity for US citizen children in immigrant families are unlikely to be successful if the issue of food insecurity and hunger is ignored.

\section{Acknowledgements}

Sources of funding: Data presented in this manuscript were collected as part of the multisite Children's Sentinel Nutrition Assessment Program. CSNAP is supported by W.K. Kellogg Foundation, Eos Foundation, Claneil Foundation, Anthony Spinazzola Foundation, US Department of Agriculture/Economic Research Service, MAZON: a Jewish Response to Hunger, Annie E. Casey Foundation, Gold Foundation, Daniel Pitino Foundation, Thomas Wilson Foundation, Sandpipers Foundation, Candle Foundation, Minneapolis Foundation, Project Bread: The Walk for Hunger, Hartford Foundation, Sue Schiro and Peter Manus, and an anonymous donor. Additional funding was provided by the Robert Wood Johnson Foundation.

Conflict of interest declaration: The authors have no potential conflicts of interest or corporate sponsorship to disclose.
Authorship responsibilities: M. K. collaborated in study design and conception, collaborated in data analysis, and wrote and edited the manuscript. J. G. managed the data and collaborated in data analysis. D. B. C. collaborated in study design and conception, and assisted in writing the manuscript.

Acknowledgements: We thank the families who participated in this study as well as all the research assistants for their dedication and advocacy. We also thank John Lantos and the CSNAP study group including the CSNAP Data Coordinating Center, Deborah Frank and Anne Skalicky for their manuscript reviews and other valuable contributions.

Preliminary results of this study were presented at the Pediatric Academic Society Annual Meeting, Seattle, WA, 5 May, 2003, and at the Robert Wood Johnson Clinical Scholar National Meeting, Fort Lauderdale, FL, 22 November, 2003.

\section{References}

1 Casey PH, Szeto K, Lensing S, Bogle M, Weber J. Children in food-insufficient, low-income families: prevalence, health, and nutrition status. Archives of Pediatrics \& Adolescent Medicine 2001; 155: 508-14.

2 Cutts DB, Pheley AM, Geppert JS. Hunger in midwestern inner-city young children. Archives of Pediatrics \& Adolescent Medicine 1998; 152: 489-93.

3 Alaimo K, Olson CM, Frongillo EA Jr, Briefel RR. Food insufficiency, family income, and health in US preschool and school-aged children. American Journal of Public Health 2001; 91: 781-6.

4 Wehler CA, Scott RI, Anderson JJ, Summer L, Parker L. Community Child Hunger Identification Project: A Survey of Childhood Hunger in the United States. Washington, DC: Food Research and Action Center, 1995.

5 Kleinman RE, Murphy JM, Little M, Pagano M, Wehler CA, Regal K, et al. Hunger in children in the United States: potential behavioral and emotional correlates. Pediatrics 1998; 101: E3.

6 Alaimo K, Olson CM, Frongillo EA Jr. Food insufficiency and American school-aged children's cognitive, academic, and psychosocial development. Pediatrics 2001; 108: 44-53.

7 Anderson S. Core indicators of nutritional state for difficultto-sample populations. Journal of Nutrition 1990; 120(Suppl. 11): 1559-600.

8 Cook JT, Frank DA, Berkowitz C, Black MM, Casey PH, Cutts DB, et al. Food insecurity is associated with adverse health outcomes among human infants and toddlers. Journal of Nutrition 2004; 134: 1432-8.

9 Kasper J, Gupta SK, Tran P, Cook JT, Meyers AF. Hunger in legal immigrants in California, Texas, and Illinois. American Journal of Public Health 2000; 90: 1629-33.

10 Himmelgreen DA, Perez-Escamilla R, Segura-Millan S, YuKuei P, Gonzalez A, Singer M, et al. Food insecurity among low-income Hispanics in Hartford, CT: implications for public health policy. Human Organization 2000; 59: 334-42.

11 Kaiser LL, Melgar-Quinonez HR, Lamp CL, Johns MC, Sutherlin JM, Harwood JO. Food security and nutritional outcomes of preschool-age Mexican-American children. Journal of the American Dietetic Association 2002; 102: 924-9.

12 Flores G, Fuentes-Afflick E, Barbot O, Carter-Pokras O, Claudio L, Lara M, et al. The health of Latino children: urgent 
priorities, unanswered questions, and a research agenda. Journal of the American Medical Association 2002; 288: 82-90.

13 Guendelman S, English P, Chavez G. Infants of Mexican immigrants. Health status of an emerging population. Medical Care 1995; 33: 41-52.

14 Reardon-Anderson J, Capps R, Fix ME. The Health and Wellbeing of Children in Immigrant Families. Washington, DC: Urban Institute, 2002.

15 Schmidley AD. Profile of the Foreign-born Population in the United States: 2000 [online], 2001. Washington, DC: US Census Bureau, Current Population Reports, Series P23-206, US Government Printing Office. Available at http://www. census.gov/population/www/socdemo/foreign/cps2000. html. Accessed August 2003.

16 Shields MK, Behrman RE. Children of immigrant families: analysis and recommendations. The Future of Children 2004; 14: 4-12.

17 Capps R, Fix M, Passel JS. The Dispersal of Immigrants in the 1990s. Washington, DC: Urban Institute, 2002.

18 Census Fact Sheet 2000: Hennepin County Foreign Born Population. Hennepin, MN: Hennepin County Office of Planning and Development.

19 Hernandez DJ. Demographic change and the life circumstances of immigrant families. The Future of Children 2004; 14: $17-47$.

20 Cook JT, Frank DA, Berkowitz C, Black MM, Casey PH, Cutts $\mathrm{DB}$, et al. Welfare reform and the health of young children: a sentinel survey in 6 US cities. Archives of Pediatrics $\&$ Adolescent Medicine 2002; 156: 678-84.

21 Hamilton WL, Cook JT, Thompson WW, Buron LF, Frongillo EA, Olson CM, et al. Household Food Security in the United States in 1995: Summary Report of the Food Security Measurement Project. Alexandria, VA: US Department of Agriculture, Food and Nutrition Service, Office of Analysis and Evaluation, 1997.

22 Bickel G, Nord M, Price C, Hamilton W, Cook JT. Measuring Food Security in the United States: Guide to Measuring Housebold Food Security. Alexandria, VA: US Department of
Agriculture, Food and Nutrition Service, Office of Analysis and Evaluation, 2000.

23 Quandt SA, Arcury TA, Early J, Tapia J, Davis JD. Household food security among migrant and seasonal Latino farmworkers in North Carolina. Public Health Reports 2004; 119: $568-76$

24 Harrison GG, Stormer A, Herman DR, Winham DM. Development of a Spanish-language version of the U.S. household food security survey module. Journal of Nutrition 2003; 133: 1192-7.

25 Kaiser LL, Melgar-Quinonez H, Townsend MS, Nicholson Y, Fujii ML, Martic AC, et al. Food insecurity and food supplies in Latino households with young children. Journal of Nutrition Education and Behavior 2003; 35: 148-53.

26 Nord M, Andrews M, Carlson S. Household Food Security in the United States, 2003. Washington, DC: Economic Research Service, United States Department of Agriculture 2004.

27 Sullivan A, Choi E. Hunger and Food Insecurity in the Fifty States: 1998-2000 [online], 2002. Waltham, MA Brandeis University, Center on Hunger and Poverty. Available at http://www.centeronhunger.org/pdf/statedata98-00. Accessed September 2006.

28 Bitler MP, Currie J. Does WIC work? The effects of WIC on pregnancy and birth outcomes. Journal of Policy Analysis and Management 2005; 24: 73-91.

29 Castner L. Trends in FSP Participation Rates: Focus on 1994 to 1998. Alexandria, VA: USDA Food and Nutrition Services, 2000.

30 Capps R, Koralek R, Lotspeich K, Fix M, Holcomb PA, Reardon-Anderson J. Assessing Implementation of the 2002 Farm Bill's legal immigrant food stamp restorations: Final report to the USDA Food and Nutrition Service. Washington, DC: Urban Institute, 2004

31 Services USCaI. Fact Sheet: Public Charge [online], 1999. Washington, DC: Press Office, US Department of Homeland Security. Available at http://uscis.gov/graphics/publicaffairs/factsheets/public_cfs.pdf. Accessed May 2005. 